العــــــــد الثانـي والأربعون

\title{
القدرة القيادية وعلاقتها بالتوجيه المدرسي لاى مديري \\ المدارس الثانوية في محافظة بغداد
}

م.د. قاسم عبدالحسين أحمد

وزارة التربية / تربية بذاد الرصافة الاولى على

0770aazz@gmail.com

المستخلص

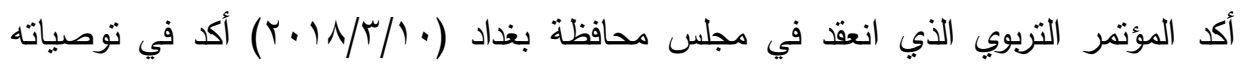
ضرورة ايجاد الحلول الازمة للمشكلات التربوية التي تخص الإدارات المدرسية وايجاد علاقات انسانية ايجابية بين إدارات المدارس وأعضاء الهيئة التدريسية لتحقيق النجاح الإداري في العمل المدرسي. ويهدف البحث الحالي التعرف على مستوى القدرة القيادية ومستوى التوجيه المدرسي لدى مديري المدارس الثانوية من وجهة نظر أعضاء الهيئة التذريسية .

وتم الاعتماد على المنهج الوصفي (الدراسات الارتباطية) وتكون مجنمع البحث الحالي أعضاء الهيئة التذريسية في المدارس الثانوية في المديرية العامة لتربية الرصافة الاولى، وتوصل البحث الى مجموعة من الاستتناجات منها ان مستوى القدرة القيادية لمديري المدارس الثانوية مقتع لحدً ما ومستوى التوجيه المدرسي غير مقنع لحٍ ما لأنه لم يكن بمستوى عالٍ قياساً بأهمية عملية التوجيه المدرسي في تحقيق الاهداف المدرسية، كما خرج البحث بمجموعة من التوصيات منها إجراء دورات تدريبية بشكل دوري لمديري المدارس الثانوية جميعهم خاصة في القيادة الإدارية اللازمة رفع قدراتهم القيادية في إدارة المدراس.

الكلمات المفتاحية: القدرة القيادية ، التوجيه المدرسي ، المدارس الثانوبة. 


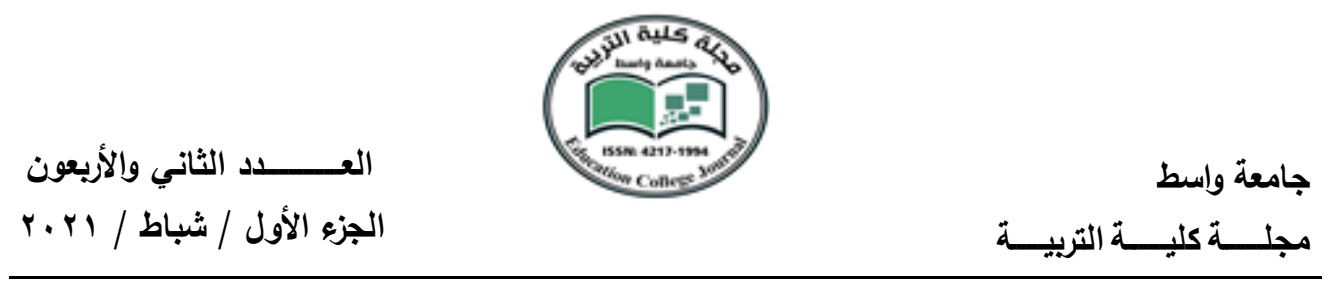

\title{
Leadership ability and its relationship to school guidance among secondary school principals in Baghdad governorate
}

\begin{abstract}
The problem of school leaderships and the extent of their proper professional preparation and their ability to achieve school goals were addressed in the educational conference held at the Baghdad Provincial Council (3/10/2018), as it emphasized in its recommendations the necessity to find solutions to the educational problems that pertain to school administrations and to create positive human relations between School administrations and faculty members to achieve administrative success in school work. The current research aims to identify the level of leadership ability and the level of school guidance of secondary school principals from the faculty members 'point of view. The descriptive approach (relational studies) was relied upon, and the current research community was members of the faculty in secondary schools at the General Directorate of Education in Rusafa Al-Awal, and the research reached a set of conclusions, including that the level of leadership ability of high school principals is convincing to some extent and the level of school guidance is not convincing to some extent Because it was not at a high level compared to the importance of the school guidance process in achieving school goals, and the research came out with a set of recommendations, including conducting periodic training courses for all high school principals, especially in the necessary administrative leadership, raising their leadership capabilities in school management, and conducting periodic training courses for school principals All secondary schools, especially in the school guidance necessary for the regular functioning of the school work.
\end{abstract}

Key words: leadership ability, school guidance, secondary schools. 
الفصل الاول

الاطار العام للبحث

مشكثة البحث

تُعد الإدارة في أي مؤسسة رأس الهرم التنظيمي وهي السبب الأول في تحقيق النجاح او الاخفاق لأن تميز أي مؤسسة يعزى إلى تميز العملية الإدارية فيها فإذا كانت إدارة المؤسسة إدارة ناجحة تكون المؤسسة في جوانبها جميعها مؤسسة ناجحة ولعكس صحيح والمدرسة مؤسسة تربوية وتعليمية يكون على رأسها مدير يكون المسؤول الأول عليها ، ويقع على عاتقه التقل ألأكبر في تشكيل إدارة فاعلة. وشهدت الإدارة المدرسية مجموعة من التغييرات التي أتضحت آثارها في تغيير مفاهيمها وأتساع مجالات العمل فيها ، وتغير دور مدير المدرسة في ضوئها من مجرد القيام بالواجبات الإدارية الروتينية والمتمثلة في المحافظة على سير العمل في المدرسة إلى قيامه بدور قيادي بارز يتجسد في كيفية التوجيه المدرسي اللازم لحل كل معوقات ومشكلات العمل المدرسي. لللك عُدت الإدارة في العقد الأول من القرن الحادي والعشرين منطلق أساسي لأي تنمية أو تقدم بالنسبة للشعوب والدول في جميع أنحاء العالم بغض النظر عن موارد الدولة مساحتها الجغرافية أو عديد سكانها ، لذا فان مسالة النجاح أو الفثل في أي مؤسسة يرجع إلى مدى قدرة القيادة الإدارية

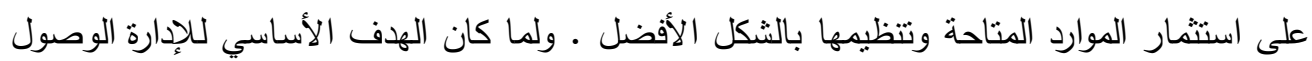
بالقيادات الإدارية إلى حال التكامل لذا ينبغي الحرص على بناء قيادات إدارية تحسن التوجيه

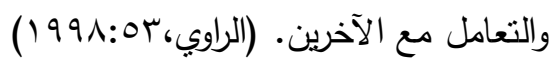

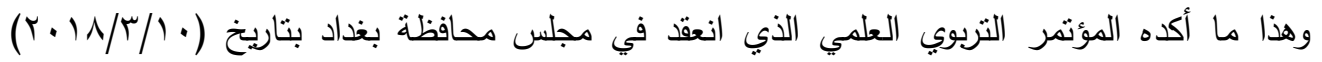
حيث أكد في توصياته ضرورة ايجاد الحلول اللازمة للمشكلات التربوية التي تعرقل سير العملية التربوية والتعليمية ومنها مشكلات الإدارات المدرسية وايجاد قيادات إدارية قادرة على بناء علاقات انسانية ايجابية بين إدارات المدارس وأعضاء الهيئة التدريسية لتحقيق الاهداف المدرسية

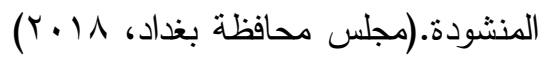
كما أكتت لجنة الاكاديميين والنخب من مؤتمرها التربوي العلمي الذي عقد في بغداد بتاريخ

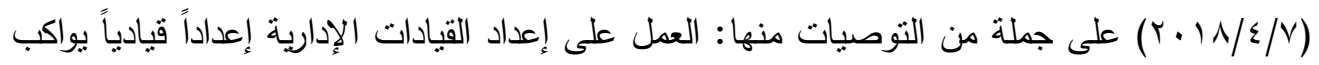
التقدم والتطور العلمي ومواجه التحديات التربوية بمهنية عالية ، فضلاً عن التأكيد على الاهتمام 
العــــــــد الثانـي والأربعون

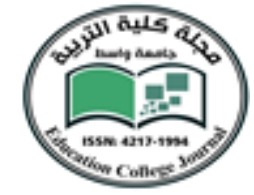

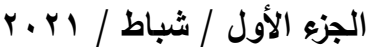

جامعة واسط

مجلــــة كليــــة التربيــــة

بالتوجيه المدرسي اللازم في العمل الإداري بما يسهم في تحقيق الأهداف المطلوبة.( لجنة الاكاديميين

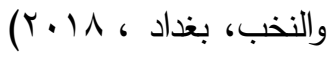

وتتبلور مشكلة البحث نتيجة للممارسات الإدارية التي يؤديها مديرو المدارس في أثتاء تعاملهم اليومي مع اعمالهم الإدارية والفنية مع أعضاء الهيئة التذريسية، لذا أصبح التعرف على مستوى القدرة القيادية والتوجيه المدرسي في المدارس الثانوية موضوعاً يحتاج الدراسة وتسليط الضوء عليه ومن هنا فإن إن إناء تقصي الحقائق عن هذا الجانب يعد من المسلمات الرائدة في هذا المجال. أهمبة البحث

المدرسة مؤسسة تربوية وتعليمية مهمة يقف المجتمع على مخرجاتها لذلك يمكن ان تعد المدرسة المصنع الكبير الي ينتج لنا الطاقات البشرية المزودة بالمعارف والمهارات المتخصصة لخدمة المجتمع وهذا ما يتطلب إدارة واعية لهذه المهمة الكبيرة تتمثل في وجود مدير يمنلك مستوى عالٍ في قدرته القيادية للمدرسة وتوجيه مدرسية ملائمة لحفظ سير العمل باتجاه تحقيق كل الاهداف المطلوبة. والمؤسسة التربوية التي تمنلك إدارة مدرسية فاعلة سنكون قادرة على التقدم والتطور في مجتمعاتها وستكون انموذجاً يقتى ويحتذى به من المؤسسات الاجتماعية والثقافية والاقتصادية الأخرى في ومسؤول الإدارة الأول في المدرسة هو المدير لذلك يتطلب قدرة قيادية واهتمام بالعلاقات الانسانية مع العاملين معه وبطبيعة الحال فإن مدير المدرسة يتعامل مع مجموعات مختلفة ومتفاعلة وهذه المجموعات هي (رؤساؤه، المدرسون، الموظفون الإداريون، الطلبة، أولياء الأمور، المجتمع المحلي.....الخ ). إذ إن الإدارة الحديثة هي ليست آلة تعمل بشكل منكرر أو نمطي بل هي علم وفن يلزمه القدرة على القيادة والتوجيه في الإدارة من أجل الإبداع في العمل لإطلاق الطاقات والامكانات عند الآخرين وإيجاد حلول للمعوقات التي تواجه العمل وتوليد أفكار جديدة مهمة للنطوير اللازم في العمل

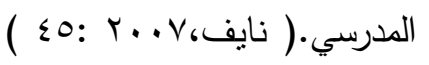

وأهم ما يميز العالم في الوقت الراهن الاهتمام بالعلم والتقدم العلمي والتكنولوجي في المجالات كافة لذلك لابد من الاهنمام بالقدرة القيادية، إذ هي الأداة الرئيسة التي تستطيع المؤسسات التربوية والتعليمية من طريق تحقيق أهدافها المنشودة ، وأن تصل إلى التكامل المرجو بين مدخلات العملية

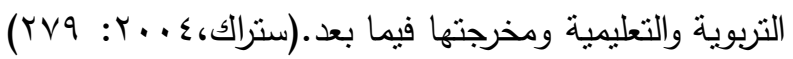


العــــــــد الثاني والأربعون

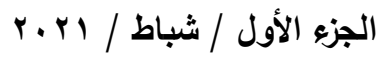

يهدف البحث الحالي التعرف على : الفئ

ا ـ مستوى القدرة القيادية لدى مديري المدارس الثانوية من وجهة نظر أعضاء الهيئة التدريسية. r. مستوى التوجيه المدرسي لدى مديري المدارس الثانوية من وجهة نظر أعضاء الهيئة التدريسية.

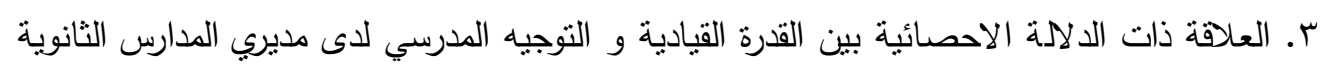
من وجهة نظر أعضاء الهيئة الندريسية. حدود البحث

الحدود البشرية : أعضاء الهيئة التنريسية في المدارس الثانوية. الحدود المكانية : المدارس الثانوية في المديرية العامة لتربية بغداد الرصافة العية الأولى.

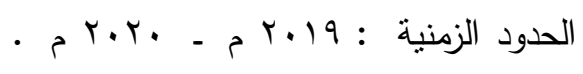

تحديد المصطلحات

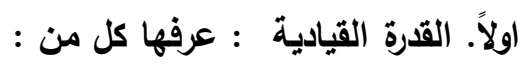

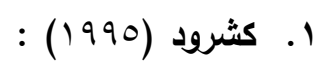

"قدرة القائد على استثمار الإمكانات والطاقات المتاحة في المؤسسة كالموارد البشرية والمادية بكل

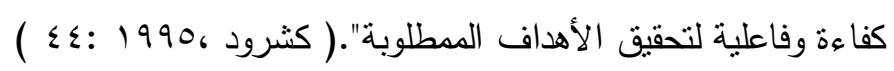

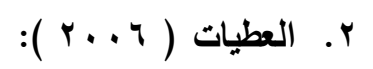

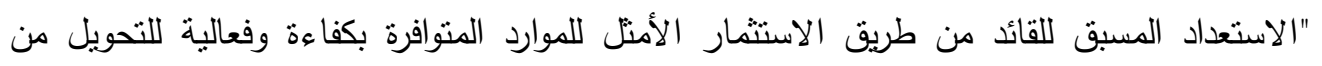

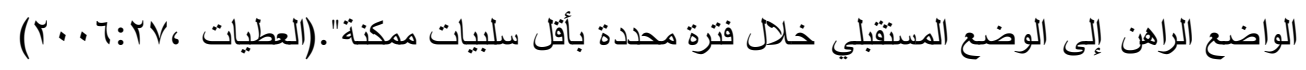

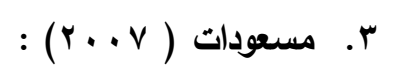
"علية تأثثر منبادل لتوجيه السلوك الإنساني داخل اطار العمل المدرسي في سبيل تحقيق هدف

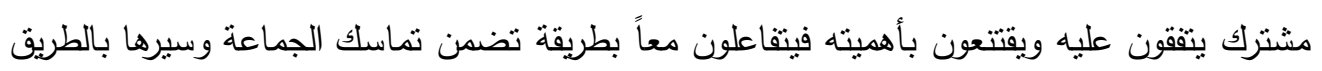

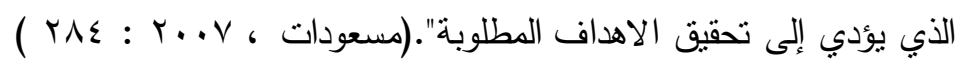
التعريف الإجرائي للقدرة القيادية قدرة مدير المدرسة على كيفية التعامل مع أطراف العمل المدرسي بشكل فاعل وبناء، وتأثيره الايجابي

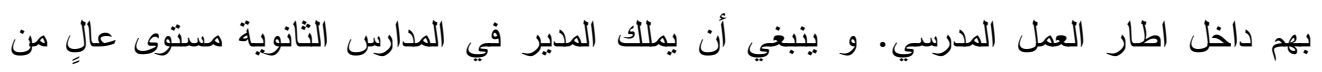




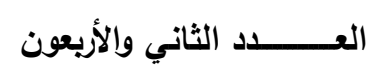

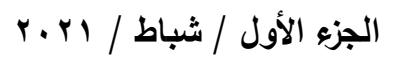

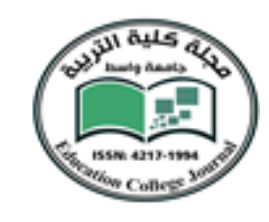

جامعة واسط

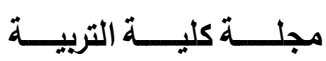

القدرة القيادية ، مقاسة بالدرجة التي يحصل عليها المدير باستجابة أفراد عينة البحث على فقرات

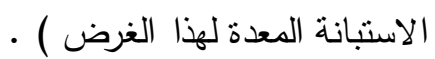
ثانياً. التوجيه المدرسي : عرفها كل من :

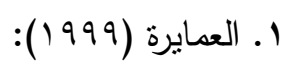

"هي عملية التفاعل الصحيح بين المدير و مرؤوسيه وتوجيه جهودهم وايجاد روح العمل الجماعي بين اعضاء الهيئة التدريسية وجعهم ينهضون بالمسؤوليات الملقاة على عاتقهم بروح يسودها التعاون

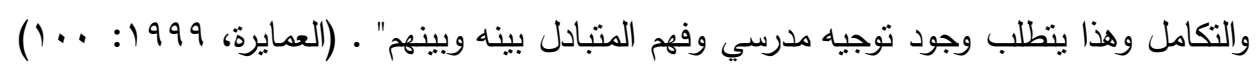

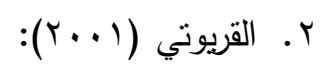
"هو ممارسة نوع من القيادة على المرؤوسين والأشراف عليهم وتحفيزهم على بذل جهود مثمرة وتنسيق جهودهم الجماعية لتحقيق الأهداف المحدة مسبقاً بإتخاذ القرارات المناسبة لهذا تتطلب مهمة التوجيه في المدير أن يؤثز في المرؤوسين بشكل يجعلهم يتصرفون على وفق الخطط المرسومة بما يحقق بلق

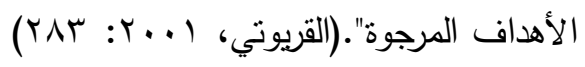

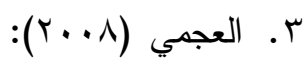

"هو عملية إرشاد وإثارة دافعية العاملين من قبل مدير المدرسة عندما يقوم بدوه كمجه باستخدام التوجيه الذي يقوم على أساس البناءوالتصحيح الذي يرتكز على العلاقات الانسانية الصحيحة".

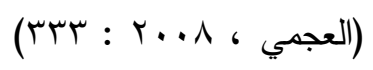
التعريف الإجرائي للتوجيه المدرسي (هو عملية ارشاد وتصحيح سير العمل من طريق التفاعل بين المدير و اعضاء الهيئة التذريسية وتوجيه جهودهم وايجاد روح العمل الجماعي وجعهم ينهضون بالمسؤوليات الملقاة على عاتقهم بروح يسودها التعاون والتكامل •و ينبغي أن يملك المدير في المدارس الثانوية مستوى عالٍ من النجاح الإداري ، مقاسة بالدرجة التي يحصل عليها المدير باستجابة أفراد عينة البحث على فقرات الاستبانة

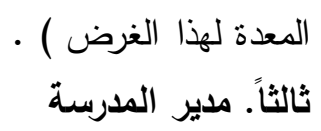

" انه أحد أعضاء الهيئة التذريسية الذي يعهد اليه إدارة المدرسة ويفضل ان يكون له خبرة لا تقل عن خمس سنوات في التذريس كشف فيه عن الكفاية العلمية والتربوية وعن القابلية للإدارة والتظظيم 
ويفضل من عمل معاونا ويفضل من حملة الثهادات الجامعية بدرجة بكالوريوس والمعد اعدادا

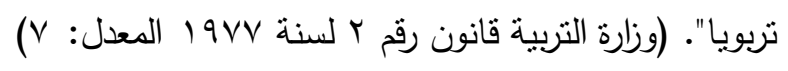
لايعاً. المدرسة الثانوية

عرفت المدرسة الثانوية على وفق نظام الددارس الثانوية رقم ب لسنة 19VV المعدل :

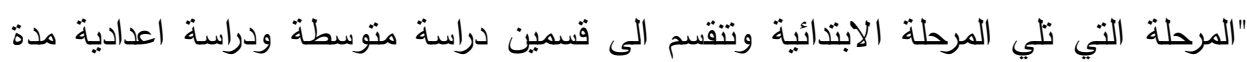

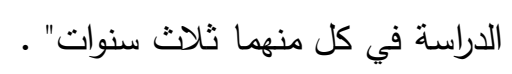
الفصل الثاني

خلفية البية ودراسات سابقة اولاً.القدرة القيادية الية ودراسيات

تتمتل القدرة القيادية في فن التأثير في السلوك لتوجيه جماعة من الناس نحو هدف معين

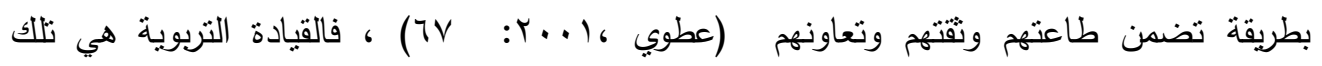

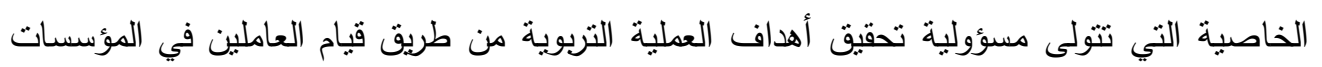

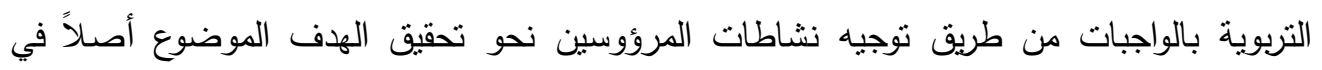

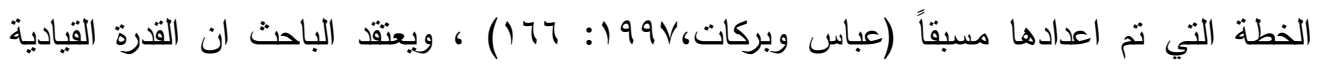

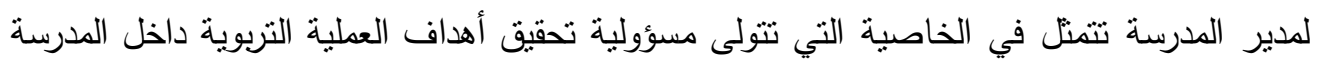

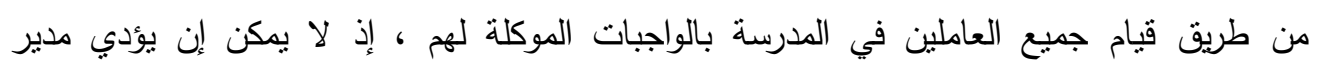

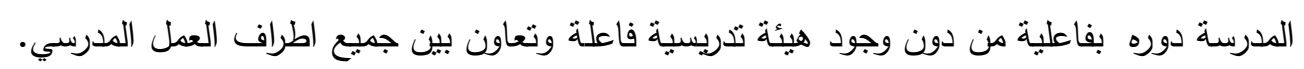

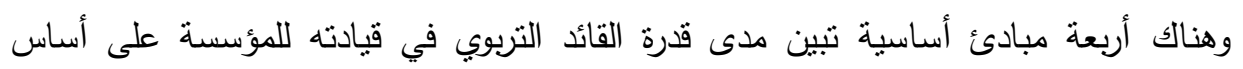

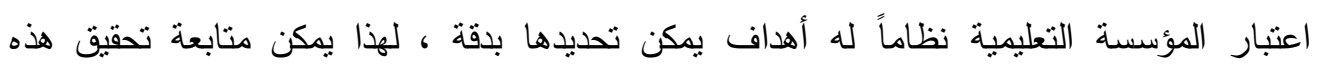

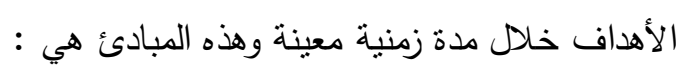

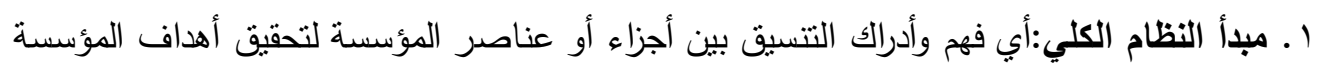

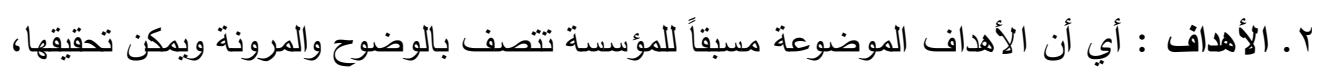
وأن تتصف بالشمولية لكي تغطي جميع مراكز المؤسسة بصورة جدية واقعية .

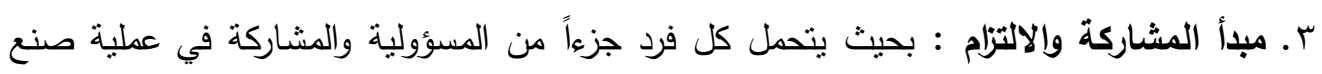
القرار من طريق توزيع الأدوار بين العاملين في المؤسسة. 
العـــــــــد الثاني والأربعون

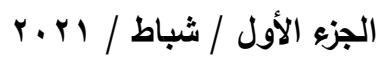

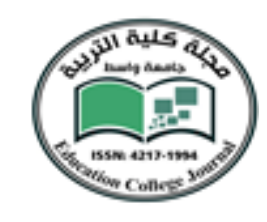

جامعة واسط

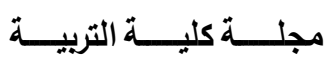

ع. مبدأ المراقبة وتقييم الأداء : وتتم عن طريق مقارنة الانجازات المتحقة مع الانجازات المخطط

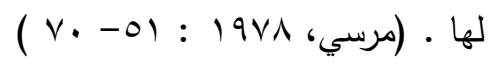

أهداف القيادة : n

ان الهذف الأساسي لقيادة أي مؤسسة تربوية وتعليمية يكمن في توجيها وتتظيمها للعاملين فيها بهدف تحقيق تفعيل جيد لمدخلات المؤسسة كافة ضمن مسعى لتحقيق أهدافها المرجوة، لذلك فأن القيادة التربوية تهدف إلى عدة أهداف ويذكر (1998، Dobel ) إن القيادة تهدف إلى :ا - تشكيل الاتجاه : وتتشكل الاتجاهات في المجموعات عن طريق توفير الروئة والاستراتيجيات الخاصة بصناعة التغيير المنشود لقيادة المؤسسة نحو النجاح . r - تنظيم الأفراد : ينتظم الأفراد العاملين عن طريق تكثيف الاتصال وتفويض المرؤوسين، فالقادة المؤثرون هم اولئك الذين ينجحون في نقل الرؤية وإستراتيجيتها إلى الأفراد المنفذين للعمل. r- التحفيز والتشجيع للأفراد : وذلك من طريق دفعهم على الطريق الصحيح من خلال مناشدة

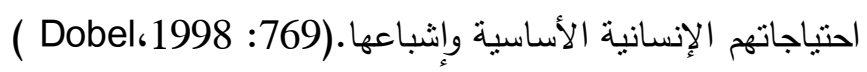
بينما يشير (Haykins,2002 ) إلى أن أهداف القيادة التربوية هي : - تحقيق أهداف المؤسسة : إي ربط رؤى المؤسسة مع نتائج الأداء معاً لمعرفة مدى تحقيق الأهداف. - المحافظة على الانسجام : وذلك من طريق بناء التقاهم المتبادل بين القائد التربوي ومرؤوسيه في المؤسسة التعليمية .

- تأصيل القيم : أنشاء مجموعة من الإجراءات والبنى التحنية لتحقيق رؤية المؤسسة التعليمية . - التحفيز : أي تشجيع المرؤوسين على انجاز أهداف المؤسسة التعليمية . - الإدارة : ويقصد بها التخطيط وحفظ السجلات ورسم الإجراءات والتنظيم بشكل مهني . - التمكين : إي إيضاح الأسباب والمبهمات في العمل للقيام بالمهام الموكلة لهم .

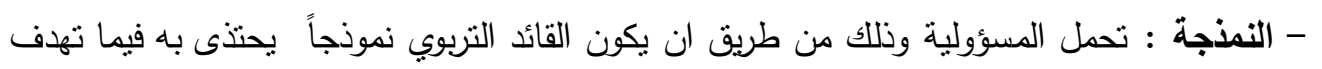
الية المؤسسة التعليمية . - إزالة العوائق : التي تقف حجر عثرة إمام تحقيق المرؤوسين لأهدافهم وظللك بتوفير الموارد المادية والبشرية اللازمة لنجاح العمل . 
- الإشراف : التأكد من مدى تحقيق المؤسسة التعليمية التزاماتها، فان لم تتحقق فعلية البحث عن

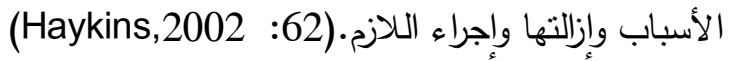

ثانياً. التوجيه

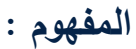

التوجيه هو ثالث العمليات الإدارية ويتمثل في إرشاد المرؤوسين أثناء تتفيذهم للأعمال الموكلة اليهم من أجل تحقيق أهداف المؤسسة، ونحتاج إلى عملية التوجيه حتى نضمن سير العمل على وفق

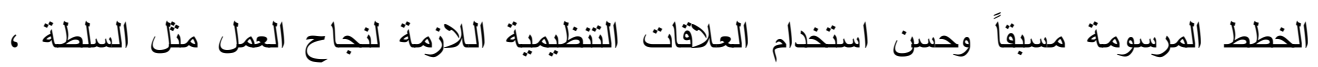
وتتمنل في القيادة - الاتصال - والتحفيز ، والأسس التي من طريقها يستطيع مدير المدرسة التوجيه وبث روح التعاون والنشاط المستمر بين العاملين في المدرسة من أجل تحقيق أهدافها. لذلك عملية التوجيه هي العملية الأساسية الثالثة في الإدارة بعد التخطيط والتنظيم ويتم التوجيه من طريق القيادة ويستوجب نلك وجود القدرة القيادية في التأثير على العاملين في المدرسة لتحقيق الأهداف المدرسية، وتوجد أساليب عدة للقيادة هي: الأسلوب الديكتاتوري، والديمقراطي و الأسلوب المتساهل، والقيادة الغير موجهة، وأسلوب الخط المستمر في القيادة. وعملية التوجيه تتعلق بتفاعل مدير المدرسة مع أعضاء الهيئة التذريسية، لذلك يحتاج ان يتعرف على شخصية العاملين معه، ويعرف كيف يعاملهم بالطريقة المناسبة ، ويعني إصدار مدير المدرسة التوجيهات والتعليمات إلى أعضاء الهيئة التدريسية لبدء العمل ولكيفية إنجازه حسب ما خطط له مسبقاً.

\section{متطلبات عملية التوجيه الصحيحة:}

ا ـ وضوح التعليمات الصادرة بحيث يتأكد الرئيس من فهم التعليمات من قبل المرؤوسين. r ـ تكامل بحيث تكون التعليمات كاملة. r. ان تكون التعليمات قابلة التنفيذ وحسب طاقة المرؤوسين. ع ـ ان تكون التعليمات والتوجيهات مكتوبة وواضحة ما أمكن.

وتحتاج الإدارة المدرسية الى وجود توجيه فاعل ومنظم من قبل مدير المدرسة لأن الإدارة المدرسية هي المنفذة للسياسة التعليمية وتعمل على تحقيق الأهداف التربوية المطلوبة وهذا يستوجب وجود إدارة مدرسية تكون بمستوى أهمية الاهداف التي تسعى إلى تحقيقها حتى تتمكن من أداء

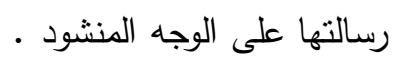


العــــــــد الثانـي والأربعون

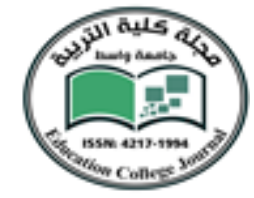

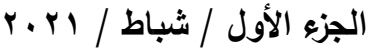

جامعة واسط

مجلــــة كليــــة التربيــــة

والإدارة الددرسية جهود منسقة يقوم بها فريق من العاملين في الدرسة ، لغرض تحقيق الأهداف

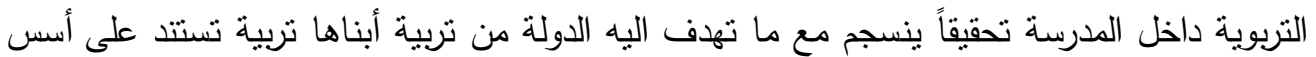
سليمة ، وهذا يعني ان الإدارة المدرسية عملية تخطيط وتوجيه لكل عمل تربوي تعليمي يحدث في

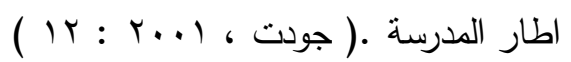

وتعد الإدارة الددرسية أداة الإدارة التربوية لتحقيق أهدافها المتنتلة في إحداث التعديلات

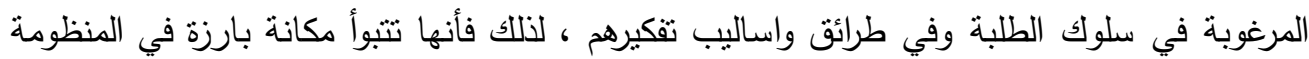
التربوية ، وقد أدى النطور الذي حث في أساليب الإدارة الددرسية وأدوارها إلى إضافة أعباء كثيرة

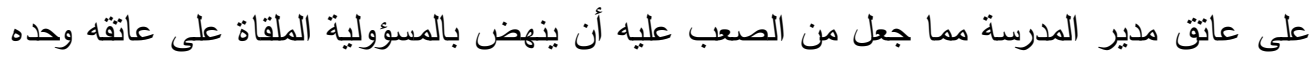

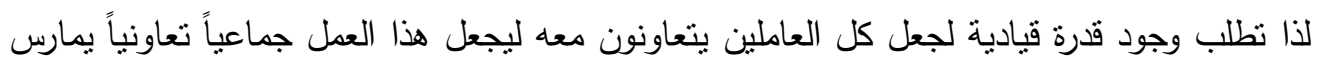

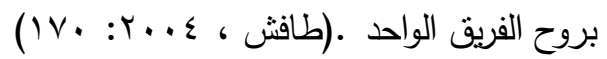

لنلك ينظلب العمل الددرسي وجود التوجيه فالمدرسون والطلبة واولياء الامور كلهم يتجهون الى آلى مدير الددرسة في ظرف وآخر طلباً التوجيه اللازم لسير العمل ، ولم تعد أهداف الإدارة الددرسية

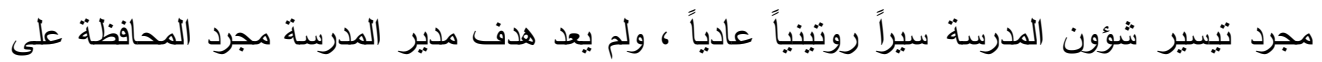

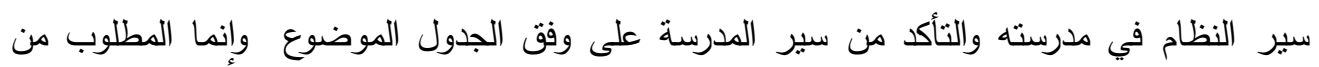

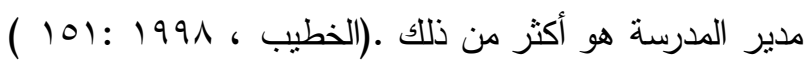

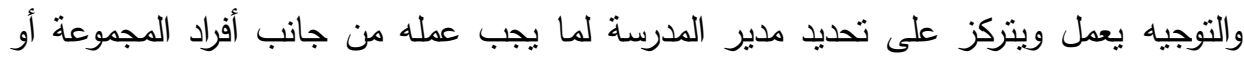

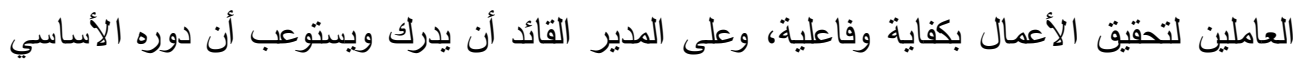

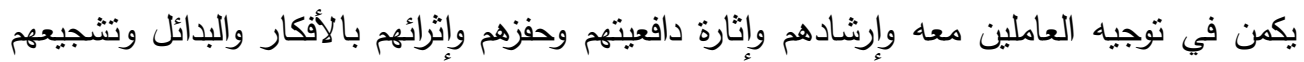

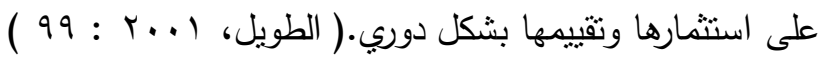

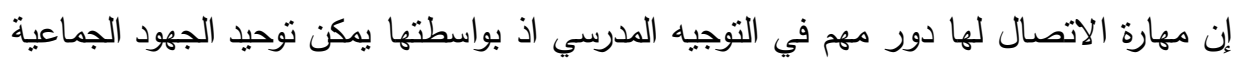

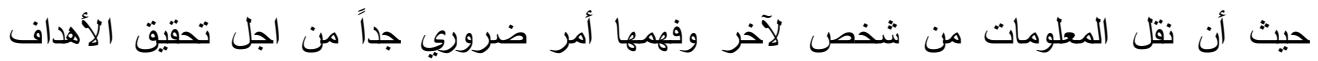

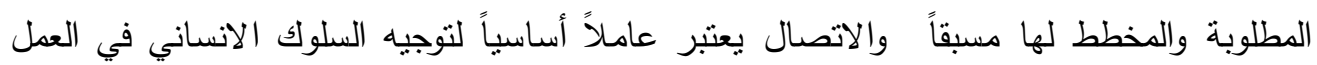

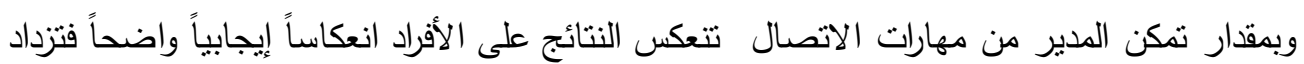

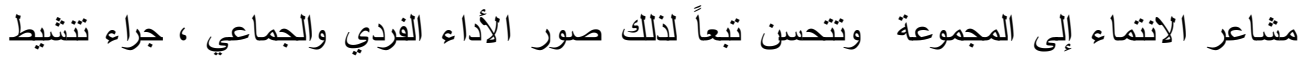

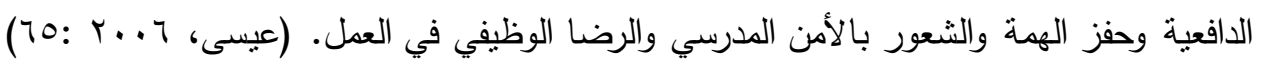


العــــــــد الثانـي والأريعون

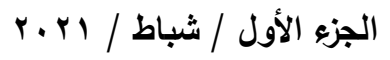

جامعة واسط

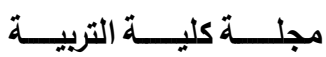

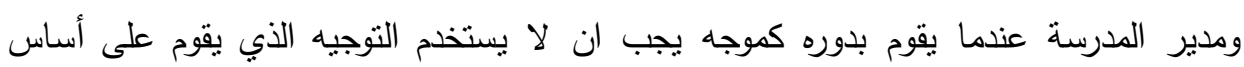

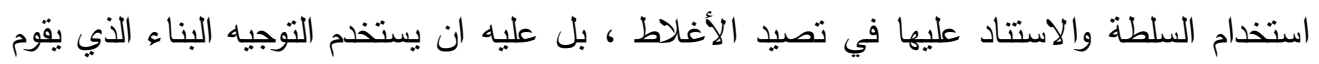

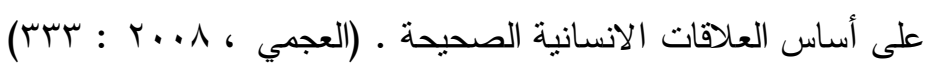

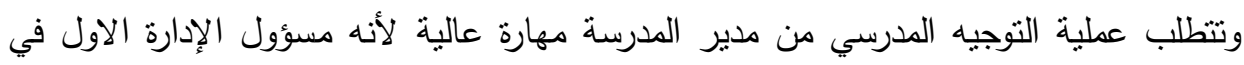

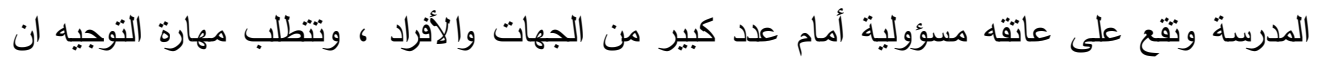
يكون للمدير تأثير في المرؤوسين بشكل يجعل عملهم يسير وفق الخطط المرسومة بما بحقق ونق الأهداف المطلوبة . المدير تانير

ويرى الباحث ان التوجيه المدرسي من قبل مدير المدرسة يجب أن يينى على عدة أمور يمكن

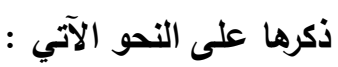
1. ـ عدم تعارض التوجيه مع القوانين والتعليمات التي تنظم عمل الدمارس.

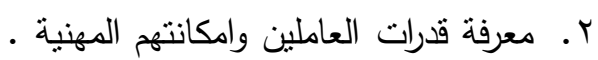
r. الابتعاد عن الجوانب الثخصية وحصر التوجيه بما ينسجم مع سير العمل الددرسي بشكل صحيح.

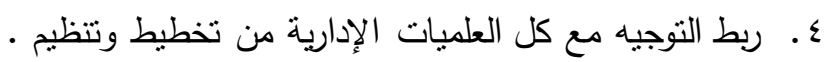
๑. التعامل الانساني يجب ان يكون هو المنطلق في عملية التوجيه مع الحرص على على ايصال مقتضيات التوجيه لكل العاملين في المدرسة. I. إن يكون التوجيه شامل لكل جوانب العمل ومبني على التنسيق اللازم للعمل المدرسي.

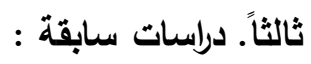
ا. الـ دراسة ايفانس وجونز (1990): "العلاقة بين السلوك القيادي للمديرين ورضا العمل للمعلمين وضغط العمل".

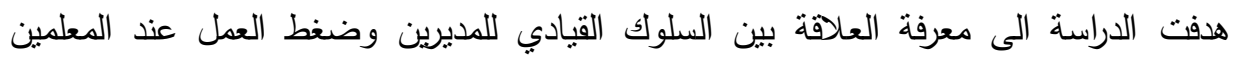

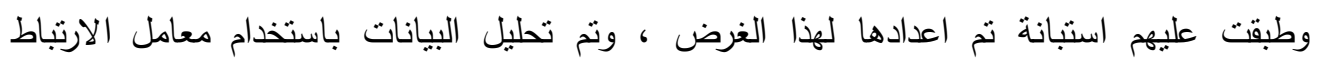

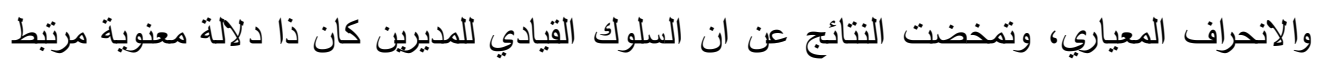
بالرضا عن العمل وضغط العمل للمعلم. اذ تبين ان المعلمين الذين لديهم مديرين يهتمون بالعمل 
العــــــــد الثانـي والأريعون

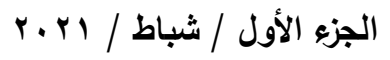

جامعة واسط

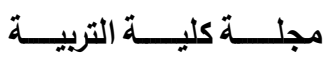

القيادي على نحو عالٍ، أو بالعلاقات الانسانية والتوجيه على نحو عالٍ، سيتعرضون لضغط عمل

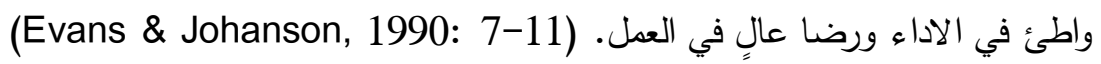

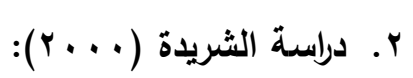

"الانماط السلوك القيادي لدى مديري المدارس الاساسية في محافظة أربد وعلاقتها بالرضا الوظيفي للمعلمين من وجهة نظر المعلمين".

هدفت هذه الدراسة الى التعرف على انماط السلوك القيادي لدى مديري المدارس الاساسية في

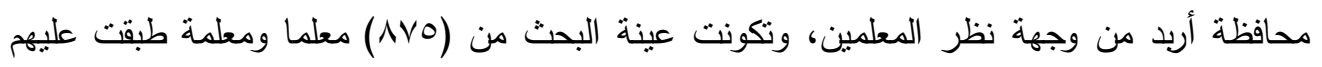

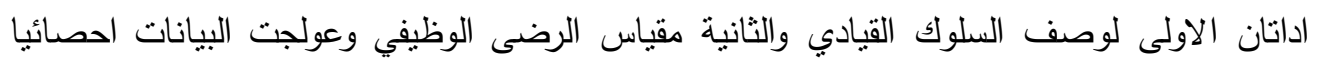

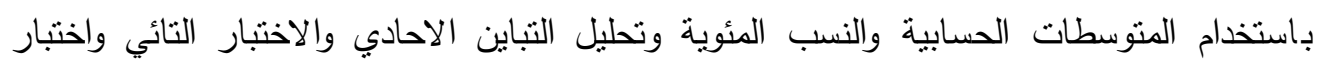

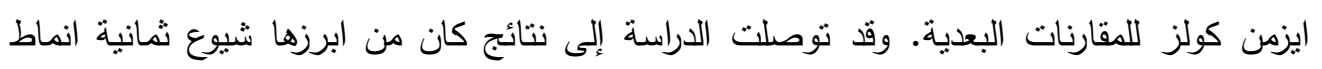

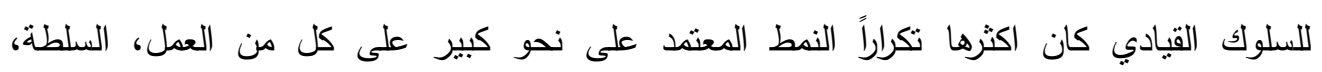

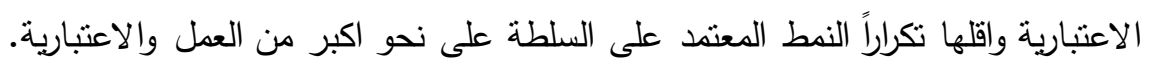

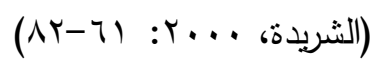

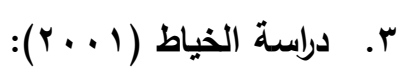

"السلوك القيادي لمديري المدارس المتوسطة وعلاقته بمستوى مشاركة المدرسين في اتخاذ القرار

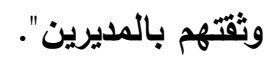
هدفت هذه الدراسة الى النعرف السلوك القيادي لمديري المدارس المتوسطة من وجهة نظر

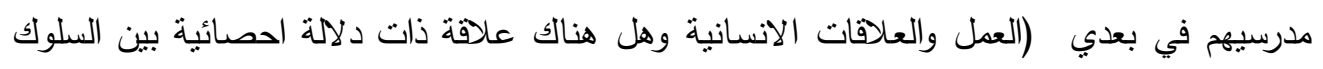

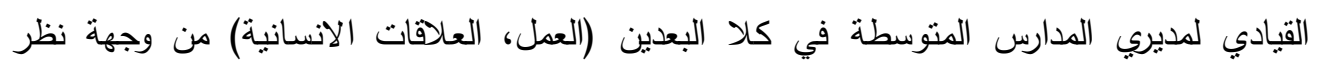

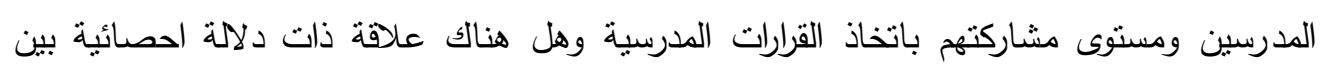
السلوك القيادي لمديري الددارس المتوسطة في كلا البعدين (العمل، العلاقات الانسانية) من وجهة

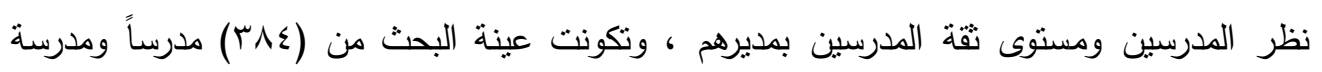
اختيروا من (Yq) مدرسة للبنين والبنات. 
اما من حيث ادوات البحث فقد استخدمت الباحثة ثلاث ادوات نم اعدادها من قبل الباحثة وبعد تحليل البيانات وباستخدام الاختبار التائي لعينتين مستقلتين ولعينتين مترابطتين، ولعينة واحدة،

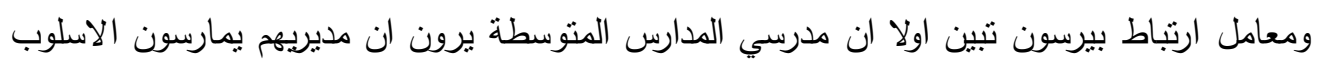

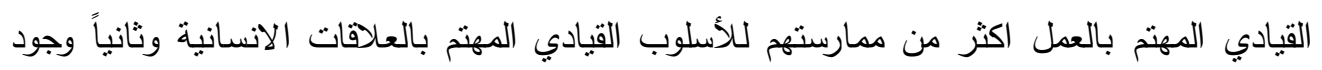

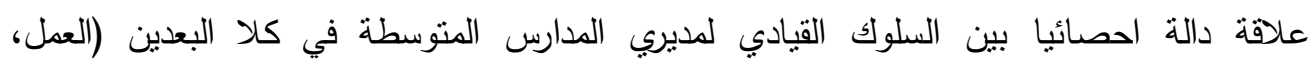

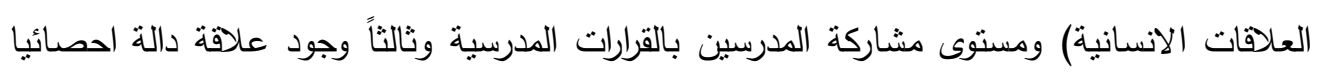

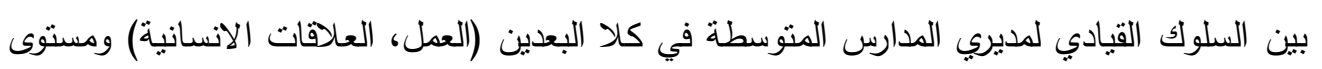

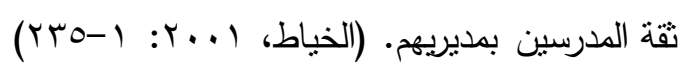

الفصل الثالث

منهج البحث وإجراء|ته

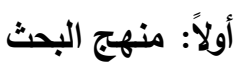

اعتمد البحث الحالي على المنهج الوصفي( الدراسات الارتباطية) ، لأنه المنهج المناسب لتحقيق

أهداف هذا البحث .

ثانياً. مجتمع البحث

يتكون مجتمع البحث الحالي من أعضاء الهيئة التخريسية في المدارس الثانوية التابعة للمديرية

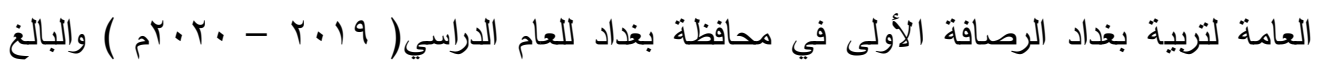

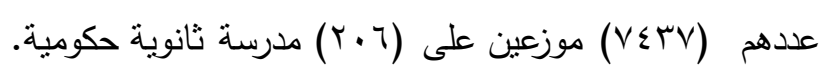
ثالثاً. عينة البحث

تحقيقاً لأهداف البحث نم اختبار العينة بالطريقة الطبقية العشوائية بنسبة (0\%) من مجتمع البحث ليكون عدد العينة (TVY) عضو هيئة التدريسية .

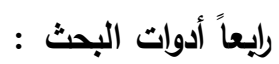
لعدم وجود أداة جاهزة تفي بالغرض فقد عد الباحث على إعداد الاستبانة استتاداً إلى الخطوات الآتية 1 ا المقابلة الثخصية . r. الاستبانة الاستطلاعية. r. الاطلاع على نظام التعليم للمدارس الثانوية والاستفادة منه بما يخص موضوع البحث. 
العـــــــد الثاني والأربعون

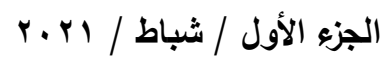

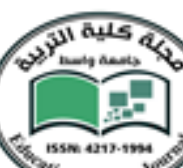

how Colless
جامعة واسط

مجلــــة كليــــة التربيـــة

ــ الاستعانة بالأدبيات والدراسات السابقة التي نم الاطلاع عليها التي لها علاقة بموضوع البحث

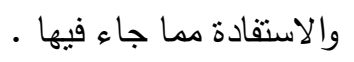

التحليل الاحصائي للفقرات

عينة التحليل الإحصائي

لغرض حساب الخصائص السيكومترية لأداة البحث الحالي طبق الباحث الأداة على العينة

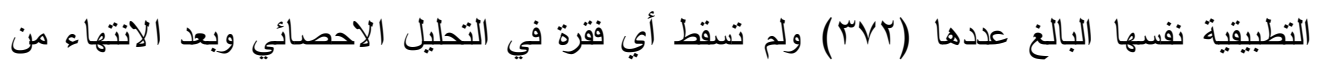

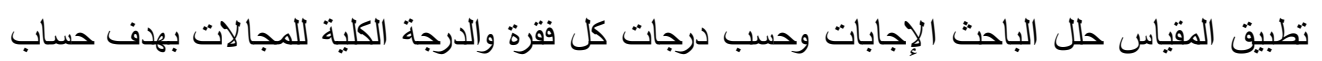

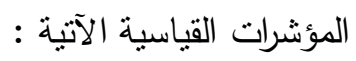

صدق الأداة الصدق الظاهري

للتحقق من صدق الاستبانة فقد عرض الباحث الأداة على مجموعة من الخبراء والمحكمين في

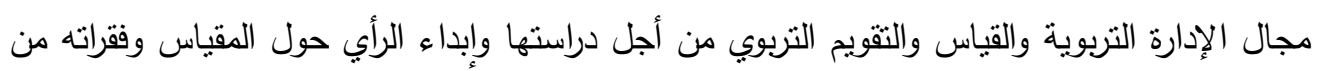

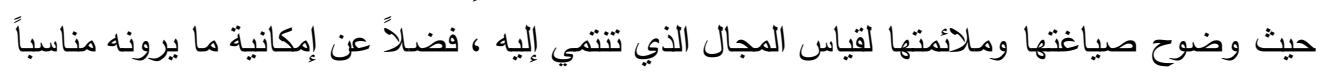
من تعديل الفقرات . صدق البناء

\section{مؤشرات صدق البناء التي تم التحقى منه :}

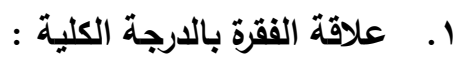

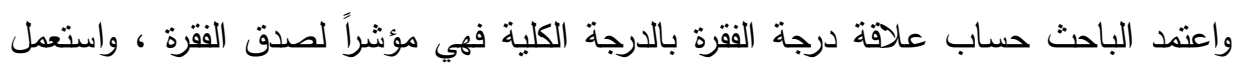

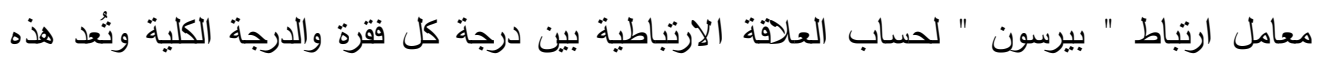

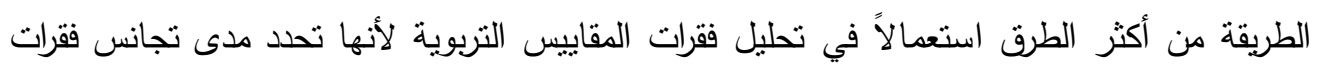

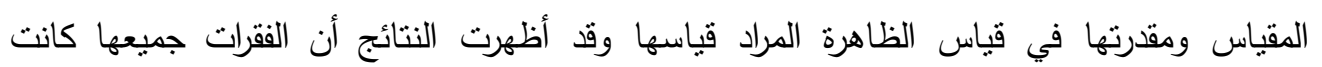
صادقة في قياس ما وضعت من أجله إذ تبين أن فقرات المقياس جميعها دالة إحصائياً عند موازنتها

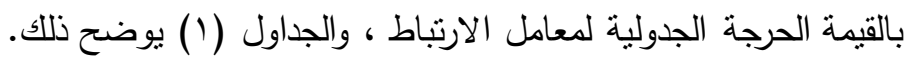


العــــــــد الثاني والأربعون

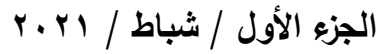

جامعة واسط

مجلــــة كليـــــة التربيــــــة

الجدول (1)

معاملات ارتباط درجة الفقرة بالدرجة الكلية للقياس القدرة القبادية

\begin{tabular}{|c|c|c|c|c|c|}
\hline معامل الارتباط & رقم الفقرة & معامل الارتباط & رقم الفقرة & معامل الارتباط & رقم الفقزة \\
\hline$\cdot, \leqslant 1$ & 10 & $\cdot, 0 Y$ & $\wedge$ & $\cdot, \leq 7$ & 1 \\
\hline$\cdot, 0 \leqslant$ & 17 & $\cdot, 0 \mathrm{~V}$ & 9 & $\cdot, V \leq$ & r \\
\hline$\cdot, \leqslant 9$ & iv & זד, . & 1. & $\cdot, \Sigma \wedge$ & r \\
\hline$\cdot, \Sigma \vee$ & 11 & $\cdot, 01$ & 11 & זד, • & $\varepsilon$ \\
\hline • & 19 & $\cdot, 9$ & ir & $\cdot, 00$ & 0 \\
\hline \multirow[t]{2}{*}{$\cdot, r q$} & $r$. &., 09 & r & $\cdot, 0$ & 7 \\
\hline & & $\cdot, 0 Y$ & $1 \varepsilon$ & $\cdot, \varepsilon r$ & V \\
\hline
\end{tabular}

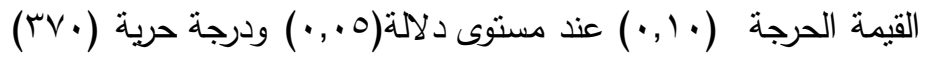

الجدول (r)

معاملات ارتباط درجة الفقرة بالدرجة الكلية لمقياس التوجيه المدرسي

\begin{tabular}{|c|c|c|c|c|c|}
\hline معامل الارتباط & رقم الفقرة & معامل الارتباط & رقم الفقرة & معامل الارتباط & رقم الفقرة \\
\hline •, or & 10 & $\cdot, 07$ & $\wedge$ & $\cdot, 7 V$ & 1 \\
\hline$\cdot, 71$ & 17 & $\cdot, 7 r$ & 9 & $\cdot, 7$. & r \\
\hline r & IV & .,Or & $1 \cdot$ & $\cdot, 0 \leqslant$ & r \\
\hline$\cdot, \pi r$ & 11 & $\cdot, 0 \mathrm{~V}$ & 11 & $\cdot, 7 \leqslant$ & $\varepsilon$ \\
\hline$\cdot, 0 T$ & 19 & $\cdot, \leq \leqslant$ & ir & $\cdot, \sum Y$ & 0 \\
\hline \multirow[t]{2}{*}{$\cdot, \leqslant 1$} & r. & $\cdot, \leqslant 7$ & Tו & $\cdot, \Sigma Y$ & 7 \\
\hline & & $\cdot, \wedge)$ & $1 \leq$ & $\cdot, T_{1}$ & V \\
\hline
\end{tabular}

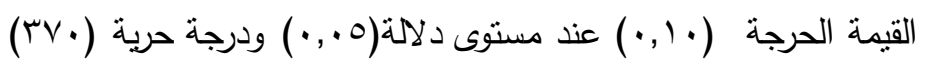


العــــــــد الثاني والأربعون

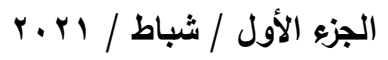

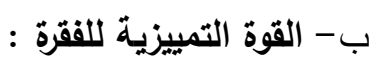

اعتمد الباحث اسلوب المجموعنين المنطرفتين في استخراج القوة التمييزية لفقرات الاستبانتين ،

وسيتم توضيحه على النحو الاتي :

أسلوب المجموعتين المتطرفتين :

بعد الحصول على الدرجات الكلية لأفراد عينة النتييز البالغة (بVآم) مستجيياً على استبانة

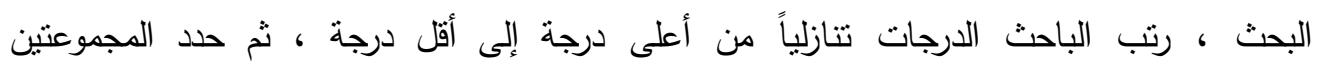

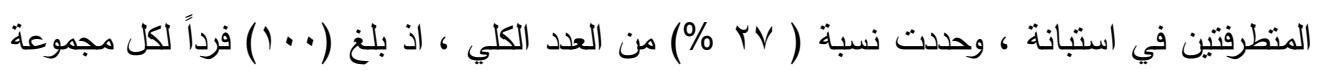

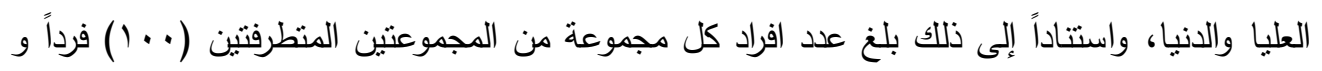

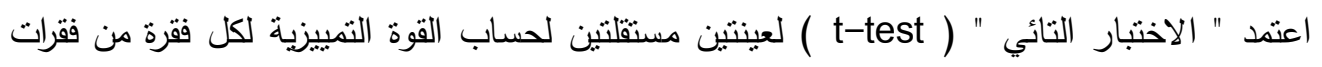
المقياس وذللك لان القيمة التائية المحسوبة تمنل القوة التمييزية للفقرة بين المجموعتين العليا والدنيا

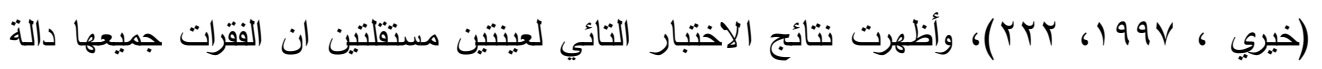

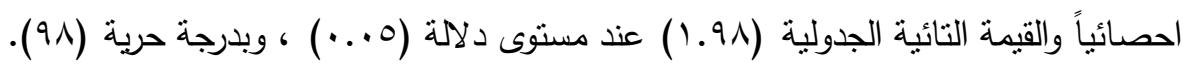

ثبات الأداة اعتمد الباحث على طريقتين في الثبات هما:

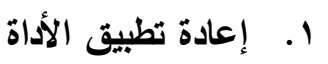

لتحقيق ذلك أختار الباحث عينة عشوائية مؤلفة من (ro) فرداً من خارج عينة البحث وتم إعادة

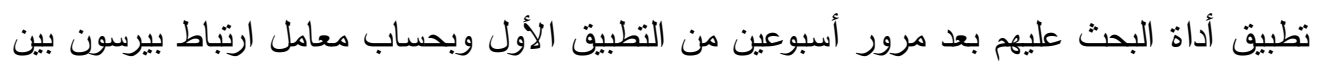

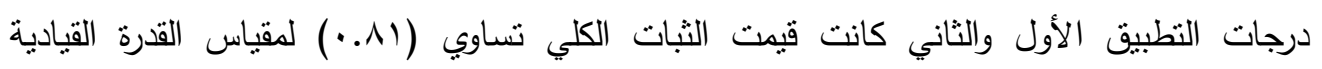
و (^^.• ) لكقياس النوجيه الدرسي ، وهذا يكثف لنا عن معامل الاستقرار في النتائج بوجود فاصل

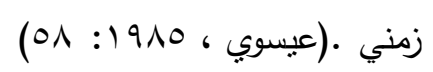

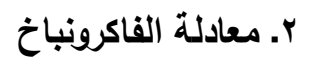

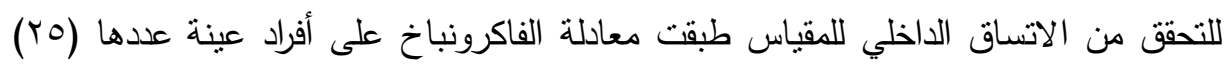

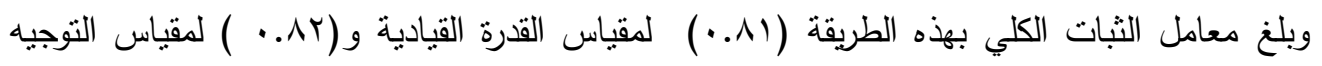
المدرسي. 
العـــــــد الثاني والأربعون

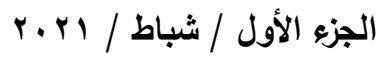

جامعة واسط مجلــــة كليــــة التزبيـــة

ان قيم معاملات الثبات على وفق الطريقتين مقبولة ، إذ تعد معاملات الثبات بصورة عامة التي

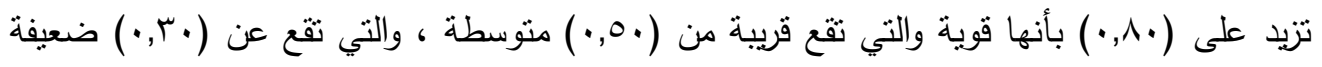

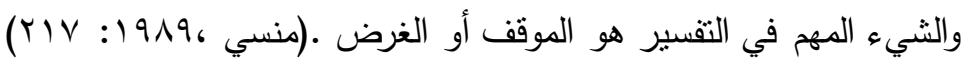

\section{وصف مقاييس البحث بصورته النهائية :}

تكون مقياس القدرة القيادية بصورته النهائية في البحث الحالي من (·r) فقرة، ومقياس

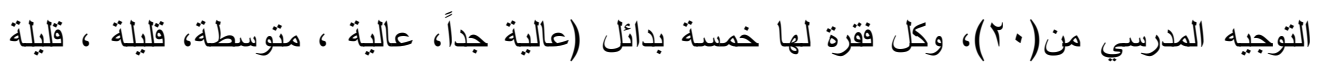

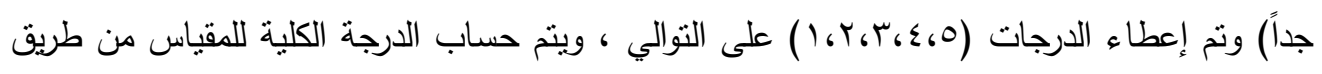

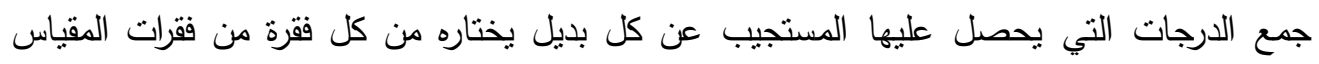

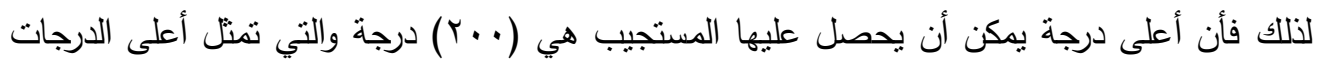
وأقل درجة يحصل عليها (•؛) درجة التي تمثل أدنى درجة كلية.

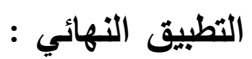
طبق مقياس القدرة القيادية والتوجيه الددرسي بصيغته النهائية على عينة البحث المؤلفة من

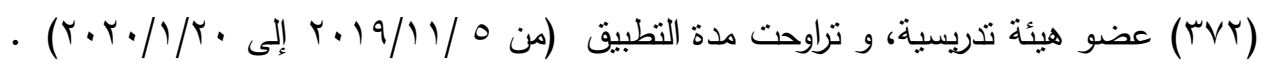

\section{الوسائل الاحصائية :}

تم استعمال الوسائل الاحصائية المناسبة في التحقق من الخصائص القياسية لمقياس البحث

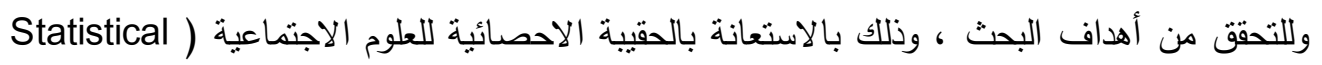

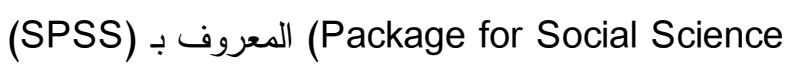




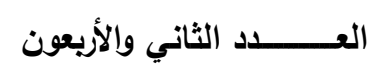

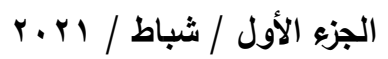

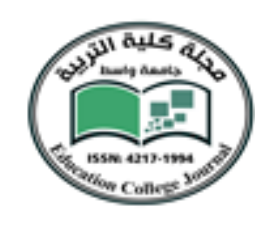

الفصل الرايع

عرض النتائج ومناقشتها وتفسيرها الهاف الأول: التعرف على مستوى القدرة القيادية لاى مديري المدارس الثانوية من وجهة نظر أعضاء الهيئة التدريسية. لغرض تحقيق الهذف الأول أستخرج الباحث الهتوسط الحسابي لدرجات عينة البحث على البى

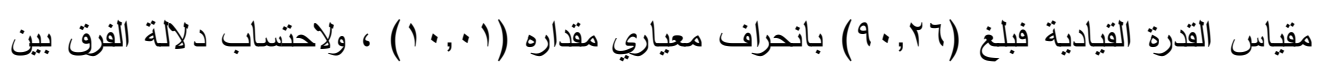

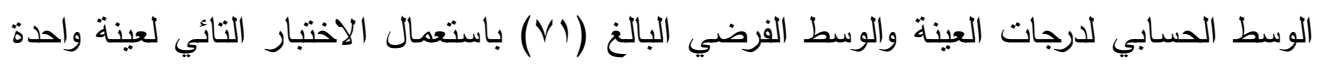
One Sample - t test

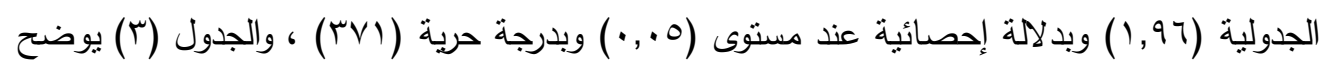
نلك.

الجدول (r)

نتائج الاختبار الثائي لعينة واحدة لمقياس القدرة القيادية

\begin{tabular}{|c|c|c|c|c|c|c|c|}
\hline \multirow{2}{*}{ مستوى } & \multicolumn{2}{|c|}{ القيمة التائية } & \multirow{2}{*}{ الحرجة } & \multirow{2}{*}{ الانحراف } & \multirow{2}{*}{ الفرضي } & \multirow{2}{*}{ المستوسط } & \multirow{2}{*}{ ألعراد } \\
\hline & الجدولية & المحسوية & & & & & \\
\hline الحصائياً & 1,97 & 0,71 & rVI & $1 \cdot, \cdot 1$ & vi & $9 \cdot, Y 7$ & TVY \\
\hline
\end{tabular}

ويتضح من الجدول (ץ) وجود فروق بين الوسط الحسابي لدرجات العينة والوسط الفرضي

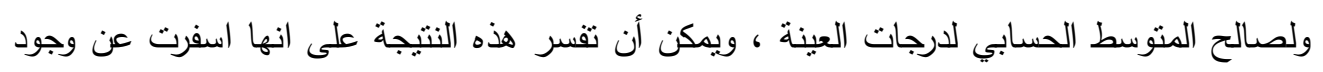

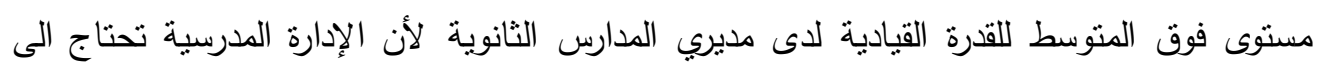

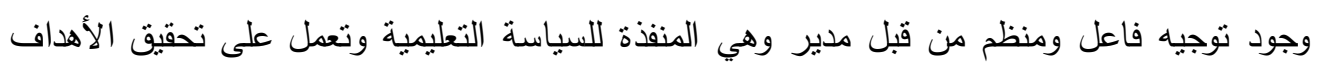

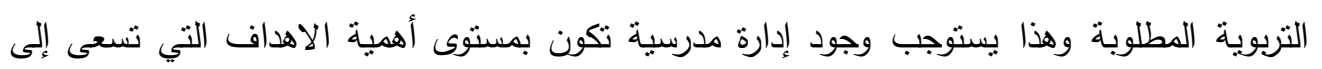
تحقيقها حتى تتمكن من أداء رسالتها على الوجه المنشود.

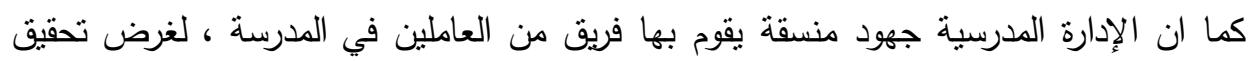

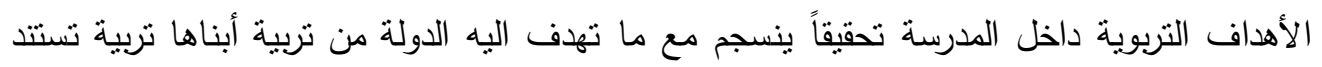


العــــــــد الثانـي والأريعون

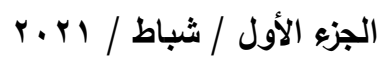

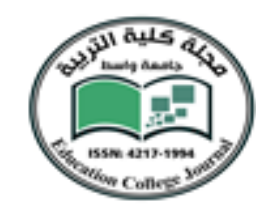

جامعة واسط

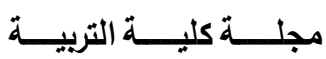

على أسس سليمة ، وهذا يعني ان الإدارة المدرسية عملية تخطيط وتوجيه لكل عمل تربوي تعليمي

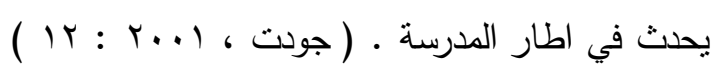

وتتقق نتائج هذه دراسة مع دراسة(الخياط) و دراسة (الشريدة) التي أسفرت نتائجهم عن وجود

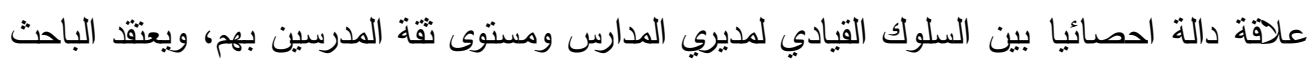
ان مديري المدارس عرفوا ان لا جدوى من إدارة المدرسة دون تأثير قيادي واضح على كل العاملين في المدرسة لذلك تشكلت لديهم مستويات من القدرة القيادية من أجل نسير العمل المدرسي وضمان تحقيق الاهداف المطلوبة والتغلب على مشكلات العمل المدرسي. الهرف الثاني : مستوى التوجيه المدرسي لدى مديري المدارس الثانوية من وجهة نظر أعضاء الهيئة التدريسية.

لغرض تحقيق الهدف الثاني الذي يرمي الى التعرف على مستوى التوجيه المدرسي فقد تم

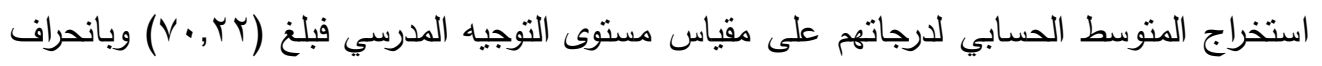
معياري مقداره (^,9^) ، ولاحتساب دلالة الفرق بين الوسط الحسابي لدرجات العينة والوسط الفرضي

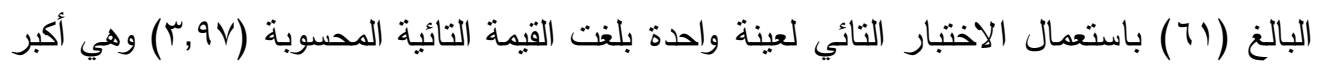

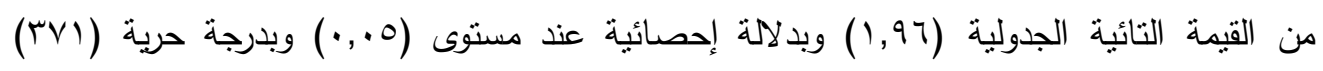
والجدول (ع) يوضح ذلك.

(飞) الجدول

نتائج الاختبار التائي لمستوى التوجيه المدرسي

\begin{tabular}{|c|c|c|c|c|c|c|c|}
\hline مستوى & & القيم & درجة & الانحراف & الوسط & المتوسط & عدد \\
\hline هـ الدلالة & الجدولية & المحسوية & الحرية & المعياري & الفرضي & الحسابي & ألعراد \\
\hline احصائياً & 1,97 & r,qV & rvi & $\wedge, 9 \wedge$ & 71 & $V \cdot, r r$ & TVY \\
\hline
\end{tabular}

ويتضح من الجدول (ع) وجود فروق بين الوسط الحسابي لدرجات العينة والوسط الفرضي ولصالح الوسط الحسابي لدرجات العينة ويمكن أن تقسر هذه النتيجة من طريق وجود مستوى منوسط مقنع نظراً لظروف الاستثنائية التي تحيط بالعمل المدرسي وقلة الدعم اللازم للإدارة المدرسية ، وغير 
مقنع لأن التوجيه المدرسي مرتبط بنطبيق الخطة المدرسية والتظيم المدرسي ولابد من وجوده

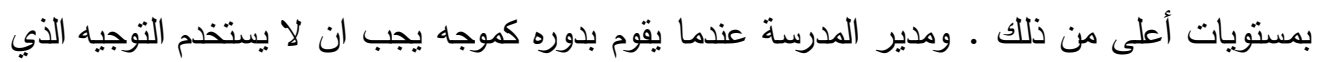
يقوم على أساس استخدام السلطة والاستتاد عليها في تصيد الأغلاط ، بل عليه ان يستخدم التوجيه

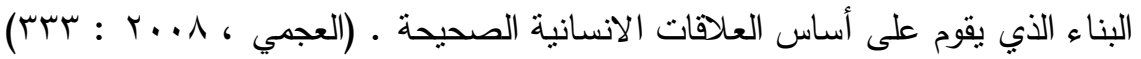
كما العمل المدرسي ينطلب وجود التوجيه فالمدرسون والطلبة واولياء الامور كله يتجهون الى مدير المدرسة في ظرف وآخر طلباً التوجيه اللازم لسير العمل ، ولم تعد أهداف الإدارة المدرسية

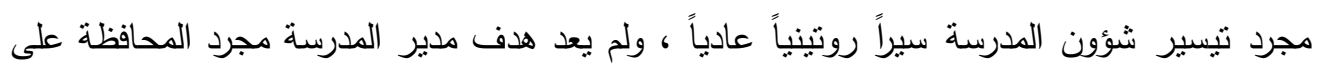

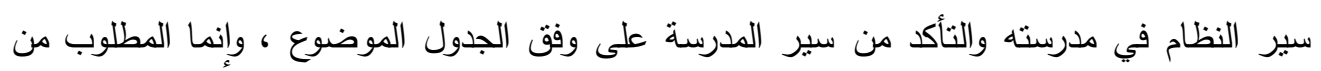
مدير المدرسة هو أكثر من ذلك .(الخطيب ، 1991 : 101 )، وتتفق نتائج هذه دراسة مع دراسة (ايفانس وجونز) اذ اسفرت عن وجود مستويات منباينة في التوجيه المدرسي.

الهذف الثالث : العلاقة ذات الدلالة الاحصائية بين القدرة القيادية و التوجيه المدرسي لدى مديري المدارس الثانوية من وجهة نظر أعضاء الهيئة التدريسية.

تحقيقاً للهدف الثالث تم حساب معامل ارتباط بيرسون بين درجات أفراد العينة على أداة تخطيط المدرسي ودرجاتهم على أداة مستوى الاداء أذ بلغت قيمة معامل ارتباط بيرسون المحسوبة (ب مـــ, •)

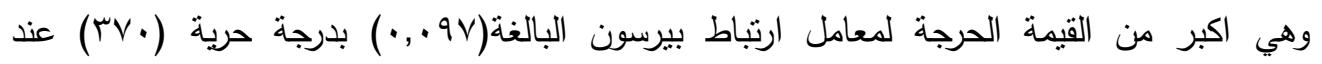
مستوى دلالة (0., ) ) ، ثمئ استعمل الاختبار لدلالة معاملات الارتباط فكانت النتائج كما مبينة بالجدول (0). 
العــــــــد الثاني والأربعون

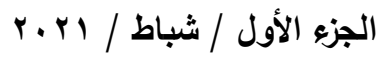

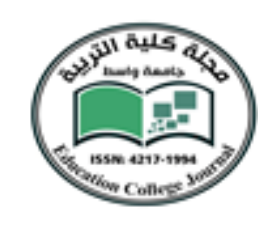

جامعة واسط

مجلــــة كليــــة التربيـــة

(0) الجدول (0)

يوضح قيمة معامل ارتباط بيرسون وقيمة الاختبار التائي لدلالة معامل الارتباط بين درجات أداتي

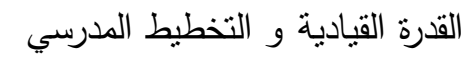

\begin{tabular}{|c|c|c|c|c|c|c|c|c|}
\hline مستوى & \multicolumn{2}{|c|}{ القيمة التائية } & \multirow{2}{*}{ مريع قيمة } & \multirow{2}{*}{ لمعامل } & \multirow{2}{*}{ قارتبياط معامل } & \multirow{2}{*}{ الحرية } & \multirow[t]{2}{*}{ العينة } & \multirow{2}{*}{ القيادية } \\
\hline 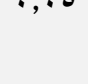 & الجدولية & المحسوية & & & & & & \\
\hline علوجة & $1,9 \mathrm{~V}$ & $1 ., 1 \vee r$ & $\cdot, .9 \xi$ & $\cdot, .9 \mathrm{~V}$ & ·, & $r v$. & TYY & الدرسيطي \\
\hline
\end{tabular}

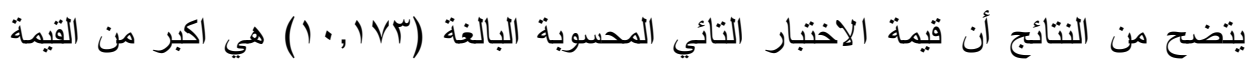

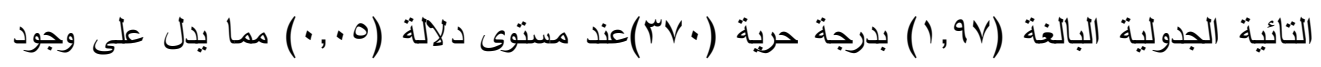
علاقة ذات دلالة إحصائية بين القدرة القيادية والتخطيط الددرسي ولتحديد مستوى العلاقة بين التين المتغيرين ربع قيمة معامل الارتباط الذي يدل على التباين المشترك بين المتغيرين فكانت النتيجة(§ •., ·) وهو يدخل ضمن المدى لنقييم معامل الارتباط.

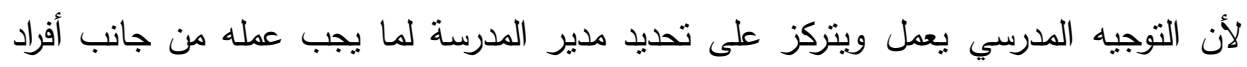

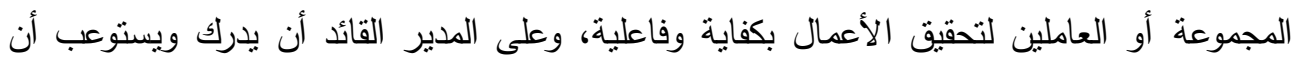
دوره الأساسي يكمن في توجيه العاملين معه وإرشادهم وإنارة دافعيتهم وحفزهم وإثرائهم بالأفكار

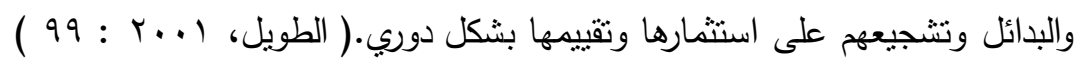

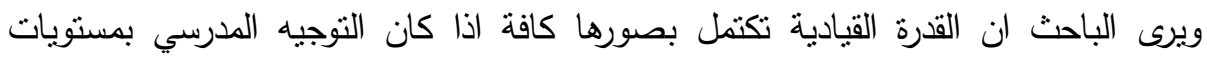

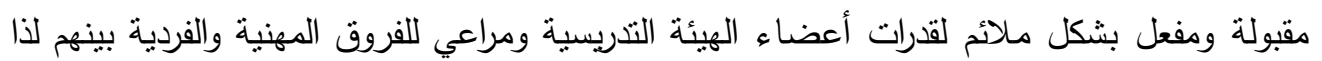
نجد وجود ارتباط وثيق بين القدرة القيادية لمدير الددرسة وتوجيهه الددرسي لكل العاملين معه في تحقيق الاهداف التي وجدت من أجلها المدرسة. 


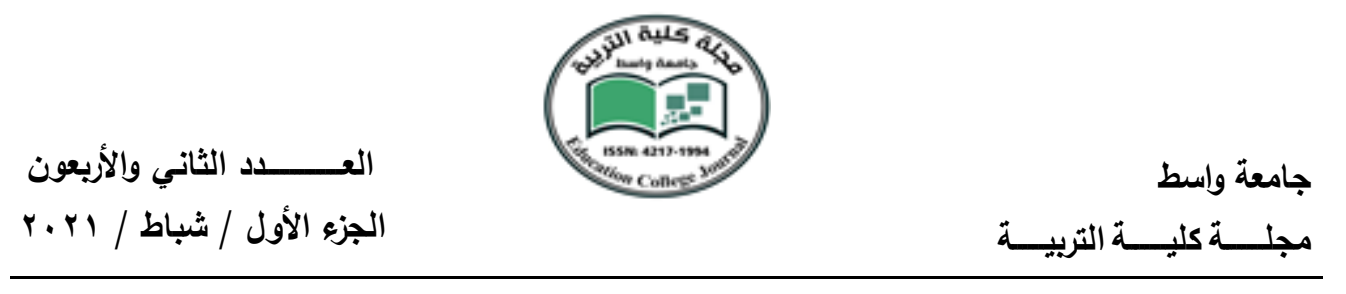

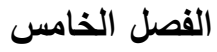

الاستتتاجات والتوصيات والمقترحات

الاستثتاجات : توصل البحث الحالي الى الاستنتاجات الآتية :

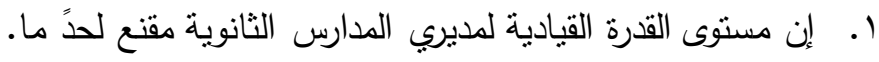
r. إن مستوى التوجيه الددرسي غير مقنع لحدٍ ما لأنه لم يكن بمستوى عالٍ قياساً بأهمية عملية التوجيه المدرسي في تحقيق الاهداف المدرسية. r. ترنبط القدرة القيادية بالتوجيه المدرسي بعلافة طردية بمعنى وجود صلة مباشرة بين مستوى القدرة القيادية للمدير ومستوى توجيهه المدرسي بنلك أي نوجيه مدرسي ينطلب قدرة قيادية من قبل مدير

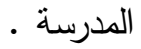

التوصيات : توصل البحث الحالي الى التوصيات الآتية : r. إجراء دورات تدريبية بشكل دوري لمديري المدارس الثانوية جميعهم خاصة في القيادة الإدارية التورية اللازمة رفع قدراتهم القيادية في إدارة المدراس. r. إجراء دورات ندريبية بشكل دوري لمديري المدارس الثانوية جميعهم خاصة في التوجيه المدرسي اللازم لتسير العمل الددرس بشكل منتظم . ـ ـ ضرورة وجود تعليمات خاصة من قبل وزارة التربية تحث مديري المدارس على الإلمام بأساسيات القيادة الإدارية. ه. على المشرف الإداري والمشرف التربوي متابعة عملية النوجيه المدرسي ومدى انتظام العلاقة

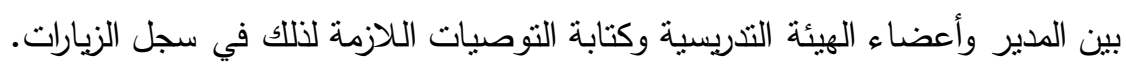
المقترحات : توصل البحث الحالي الى المقترحات الآتية :

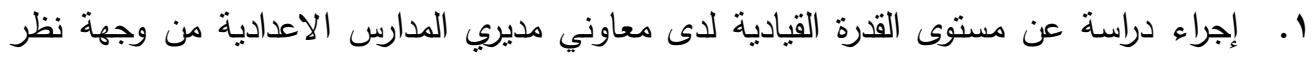
مديريهم. r r. إجراء دراسة عن التوجيه الدرسي وعلاقته بمستوى الاداء لدى مديري المدارس الثانوية. r. إجراء دراسة عن القدرة القبادية وعلاقتها بالسمات الثخصية لمديري المدارس الثانوية. 
ا. جودت ، عزت ، (1 . ب). الإدارة المدرسية الحديثة مفاهيمها النظرية وتطبيقاتها العلمية ، الاردن ، دار التقافة

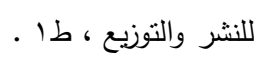

r. الخطيب ، عامر يوسف ، (991) (191). إستراتيجية مقترحة لتربية الموهوبين ، مجلة التربية ، الجمعية المصرية للتربية

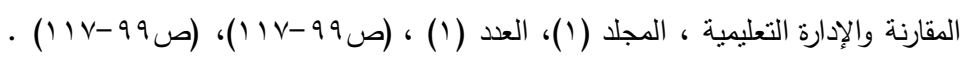

r. الخياط ، اسماء عبدالرحيم خضر (1) (ب). السلوك القيادي لمديري المدارس المتوسطة وعلاقته بمستوى مشاركة المدرسين في اتخاذ القرار وثقتهم بالمديرين، جامعة الموصل، كلية التزبية، اطروحة دكتوراه. ع. خيري ، السيد محمد (199V) ـ الاحصاء النفسي ، دار الفكر العربي ، القاهرة.

ه. الراوي ،حقي اسماعيل(1991 ). بناء انموج لتحسين المستوى للمرشدين التربويين في التربية الارشاد التربوي ،كلية التربية الجامعة المستتصرية (اطروحة الدكتوراه غير منشورة).

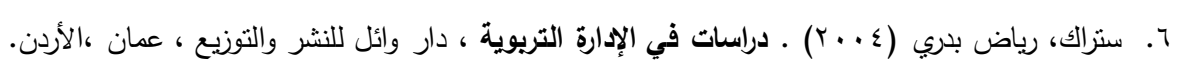

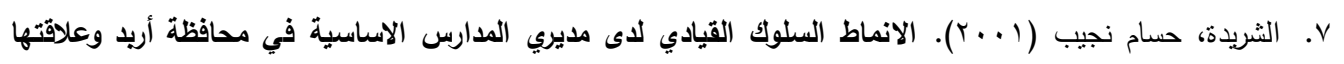
بالرضا الوظيفي للمعلمين من وجهة نظر المعلمين، اتحاد الجامعات العربية، العدل ها، عمان، الاردن. ^. طافش ، محمود، ع . . r. الإبداع في الإثراف والإدارة المدرسية، دار الفرقان للنشر، عمان، الأردن.

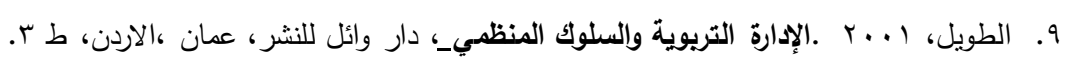

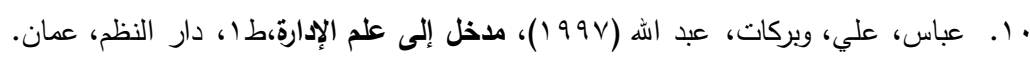

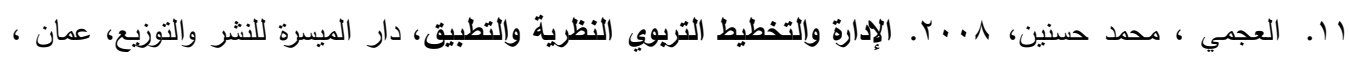
$.1 \mathrm{~b}$

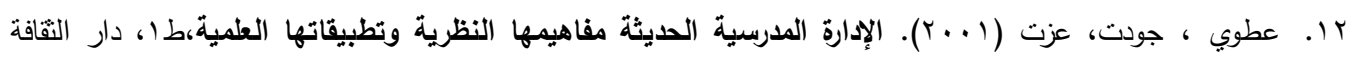
للنشر والتوزيع، عمان.

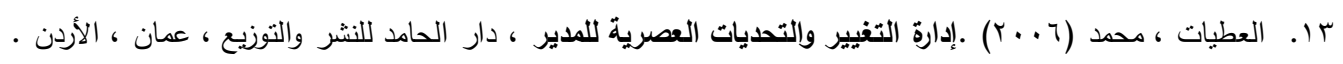

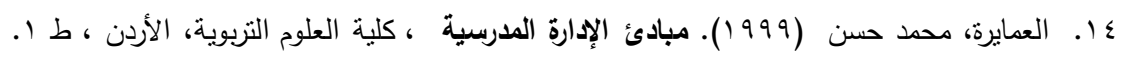
10. عيسوي ، عبد الرحمن محمد (1910) .القياس والتجريب في علم النفس والتربية ، دار المعرفة الجامعية، القاهرة.

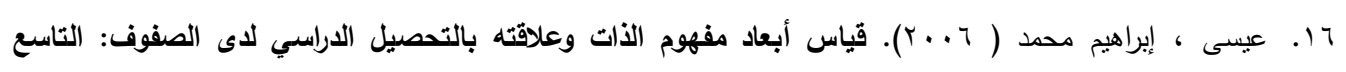
والعاشر والحادي عشر في الأردن، مجلة اتحاد، لأردن.

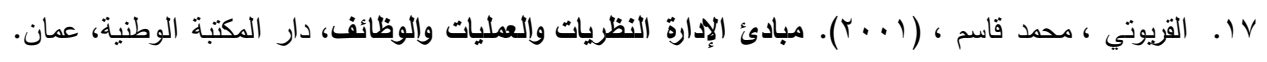




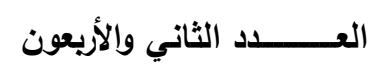

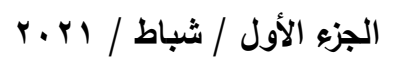
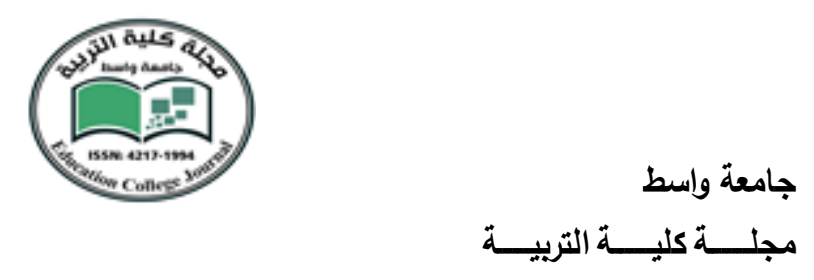

11. كثرود ، عمار (1990) . علم النفس الصناعي والتنظيمي الدديث مفاهيم ونظريات ، منشورات جامعة قار يونس ،

بنغازي ، ليييا .

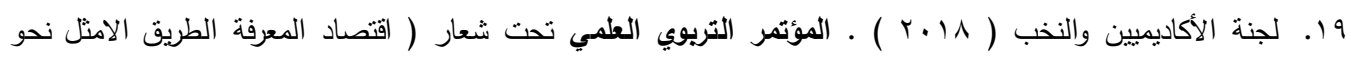

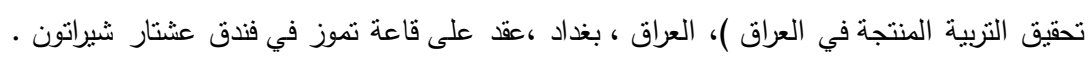

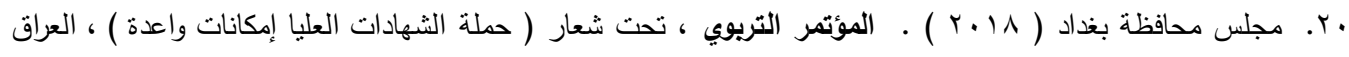
، بغداد ، عقد على قاعة الرافدين في مجلس محافظة بغداد بتعاون مع المركز العراقي للاراسات التربوية.

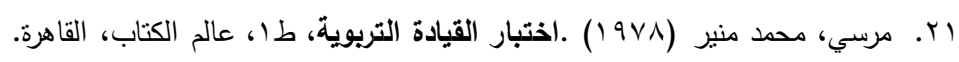

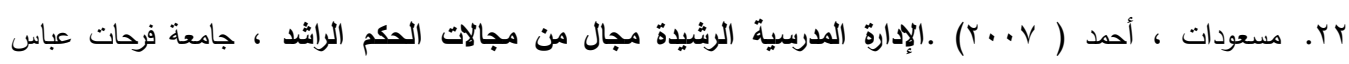
سطيف ، الجزائر مبرد

rr. منسي ، محمود عبد الحليم (919 (19) • الإحصاء والقياس في التربية وعلم النفس ، دار المعرفة الجامعية ، مصر.

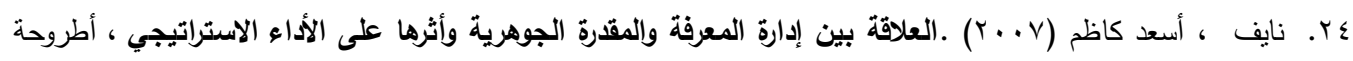

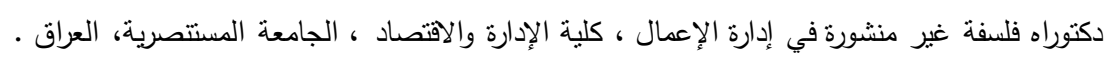

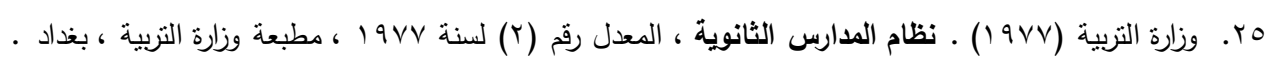

26.Dobel ,(1998), Political Prudence and The Ethics of Leadership , Public Administration Review ,Vol.58,No.1.

27.Evans, V. \& Johnson, D.J. (1990): The Relationship of principals Leadership behavior and teachers job satisfaction and job related stress, Journal if In Structional psychology, Vol.17, 11-19.

28.Haykins, T, L. (2002). Principal leadership and organization climate: a study of perceptions of the leadership behavior on school climate in international school Dissertation Abstract Inte rnational, 62. 